\title{
A INTERATIVIDADE E O PAPEL DA PEER INSTRUCTION NO ENSINO E APRENDIZAGEM DA FÍSICA
}

\author{
Paulo Simeão CARVAlHO* \\ Departamento de Física e Astronomia, IFIMUP-IN, UEC, \\ Faculdade de Ciências da Universidade do Porto, Rua do Campo Alegre, s/n, \\ 4169-007 Porto, Portugal
}

\begin{abstract}
Resumo
A Peer Instruction - ou Instrução pelos Colegas (IpC) - é considerada uma das grandes novidades pedagógicas do final do século XX. Trata-se de uma abordagem didática na qual o professor cria condições, no decurso da prática letiva, para que os estudantes tenham uma participação ativa na construção do conhecimento. A origem desta prática assenta na discussão das ideias e remonta à época Socrática (V a.C.), num contexto de reconhecimento da importância da verbalização e do questionamentosobre os valores da sociedade, na construção da Ciência e na interpretação do Mundo Natural. A IpC como abordagem didática reflete uma preocupação dos professores e dos agentes educativos em conhecer os modelos mentais dos estudantes e promover a sua aproximação aos modelos físicos atualmente aceitos. A aplicação da IpC na sala de aulas segue uma sequência estruturada com algum grau de flexibilidade. A sua implementação é facilitada por vários fatores processuais e logísticos, comuns a muitas outras abordagens que estão em sintonia com um ensino interativo. Este é o foco do trabalho que aqui se apresenta.
\end{abstract}

Palavras-chave: peer instruction; Instrução pelos Colegas; ensino interativo; modelos mentais; mapas conceptuais; recursos educativos digitais.

*E-mail: psimeao@fc.up.pt; Web: http://www.fc.up.pt/pessoas/psimeao/ 


\begin{abstract}
Peer Instruction - or Instruction by Colleagues $(I b C)$ - is considered one of the great pedagogical innovations of the late twentieth century. It is a didactic approach in which the teacher creates conditions, in the course of teaching practice, so that students have an active participation in the construction of knowledge. The origin of this practice is based on the discussion of ideas process and goes back to the Socratic period ( $V$ a.C.), in a context of recognition of the importance of verbalization and questions about the values of society, in the construction of Science and in the interpretation of the Natural World. IbC as a didactic approach reflects a concern of teachers and educational agents to know the mental models of the students and to promote their approach to the currently accepted physical models. The application of IbC in the classroom follows a structured sequence with some degree of flexibility. Its implementation is facilitated by several procedural and logistical factors, common to many other approaches that are in tune with an interactive teaching. This is the focus of this paper.
\end{abstract}

Keywords: peer instruction; interactive learning; mental models; conceptual maps; digital educational resources.

\title{
1 INTRODUÇÃO
}

Ensinar não é o mesmo que aprender. Ensinar é um ato inerente a quem transmite algo (o professor), enquanto o aprender é uma faculdade pessoal de quem recebe esse algo (o estudante) (CARVALHO, 2015). O objetivo último do processo educativo e, por inerência, dos professores, é que o ensino produza aprendizagem efetiva - um processo que, falando sério a brincar, FILHO (2017) designa por Ensinagem.

A origem do ato de aprender por discussão remonta à Grécia do século V a.c. e à Escola Socrática (SERZEDELLO, 2012). Esta escola primitiva da Grécia Antiga, cujo conhecimento chegou até nós através dos diálogos de Platão (JOWETT, 1911) e pelos escritos de Aristóteles, influenciou profundamente o pensamento científico e em particular a forma de compreender o Mundo Natural (PIRES, 2008). Sócrates percebeu que as pessoas aprendem melhor chegando por elas próprias a uma conclusão, do que obtendo a resposta de outros (ABRAHAMSON, 1998). O que está na essência do diálogo socrático é uma atividade cooperativa, em que indivíduos com diferentes experiências de vida e graus de conhecimento procuram chegar a uma convergência de ideias.

Transpondo para o ensino e aprendizagem das ciências e em particular da Física, as ideias que os alunos têm sobre o conteúdo conceptual, as relações ente conceitos, as leis e a correspondente interpretação fenomenológica, constituem aquilo que Johnson-Laird designou por modelos mentais (JOHNSON-LAIRD, 1983), representações internas construídas pelas pessoas para captar o mundo que as rodeia. Estas representaçõessãoesquemas particularmente robustos e coerentes, que se moldados num conjunto de ideias consistentes acerca dos objetos físicos e suas propriedades, são considerados como um modelo físico 
(BAO; REDISH, 2001). Esses conteúdos da ciência estão invariavelmente agrupados em conjuntos coerentes designados por campos conceptuais (VERGNAUD, 1990; MOREIRA, 2002).

Assim, a ensinagem não é mais do que o resultado da aproximação dos modelos mentais dos alunos, aos modelos científicos atualmente aceites, tendo por base um determinado campo conceptual; é o que Hestenes designa por estratégia de modelação, no enquadramento de uma teoria de modelação (HESTENES, 1987; ETKINA; WARREN; GENTILE, 2006).A grande dificuldade dos professores está, assim, em conhecer o modelo mental de cada um dos seus alunos, pois cada um tem o seu e isso traduz diferentes perceções da ciência.

Não é fácil descobrir a fórmula de obter o modelo mental de cada indivíduo - é necessário que ele participe nas discussões, explicite as suas ideias e confronte os seus comentários com os dos outros. Uma forma de promover essa participação em sala de aula, é selecionar campos conceptuais de pequena dimensão (5 a 10 conceitos), organizar os conceitos numa estrutura hierárquica e trabalhar (em pequeno ou em grande grupo) as relações entre eles, de forma a que, no final, seja possível construir frases inteiras que traduzam ideias cientificamente coerentes. Esta construção hierárquica, que constrói com significado as ideias científicas, designa-se por Mapa de Conceitos, MC (NOVAK; GOWIN, 1996) e tem como base a teoria da aprendizagem significativa de Ausubel (AUSUBEL, 1968).

A Figura 1 é uma representação genérica de um MC. No topo da árvore conceptual encontra-se o conceito com maior grau de generalidade ou abrangência; os conceitos que se encontram hierarquicamente abaixo têm maior especificidade. Cada conceito hierarquicamente mais elevado serve de âncora (conceito subsunçor) do(s) que se lhe segue $(\mathrm{m})$. As ligações entre conceitos (palavras que ligam os conceitos e que dão significado às setas) são uma peça-chave do MC, pois são elas que verbalizam o modelo mental do indivíduo, criando uma estrutura do conhecimento assente na lógica, coerente e com significado, promovendo assim a mudança / consolidação conceptual e a construção do conhecimento científico.

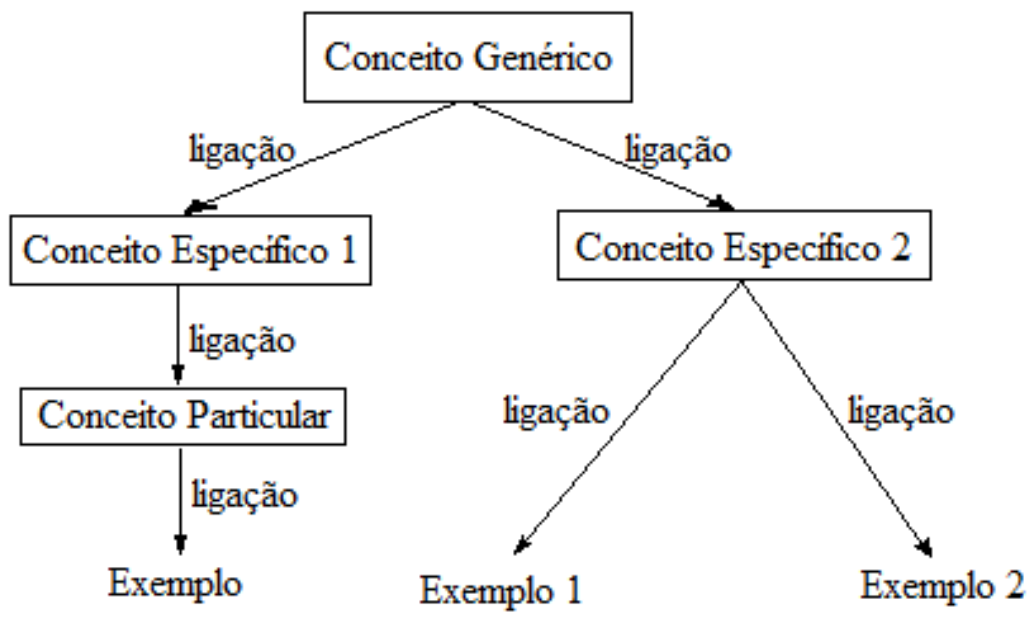

Figura 1: Representação esquemática de um Mapa de Conceitos.

A implementação de um mapa conceptual na sala de aulas, pode ser feita através de uma sequência simples como a indicada na Figura 2. Cabe, naturalmente, ao professor decidir quando e como o fazer, tendo em conta os seus objetivos didáticos. 


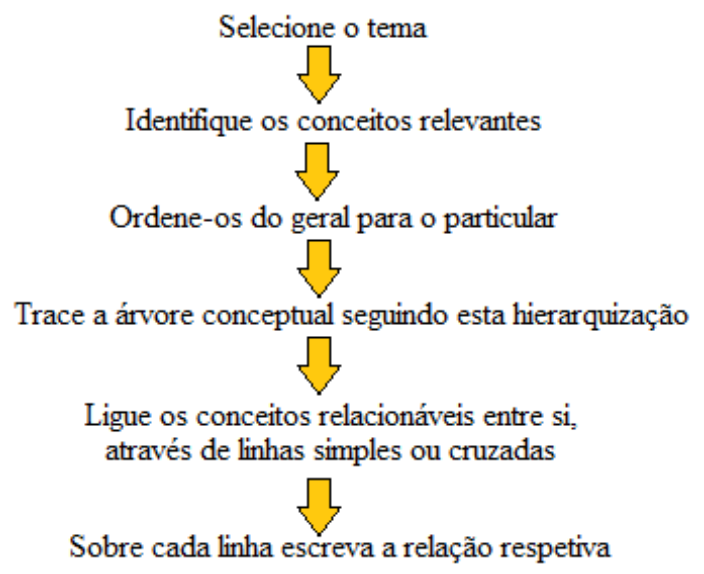

Figura 2: Esquema da implementação de um MC em sala de aulas.

Um exemplo de um MC é apresentado na Figura 3, tendo como base um campo conceptual da cinemática.

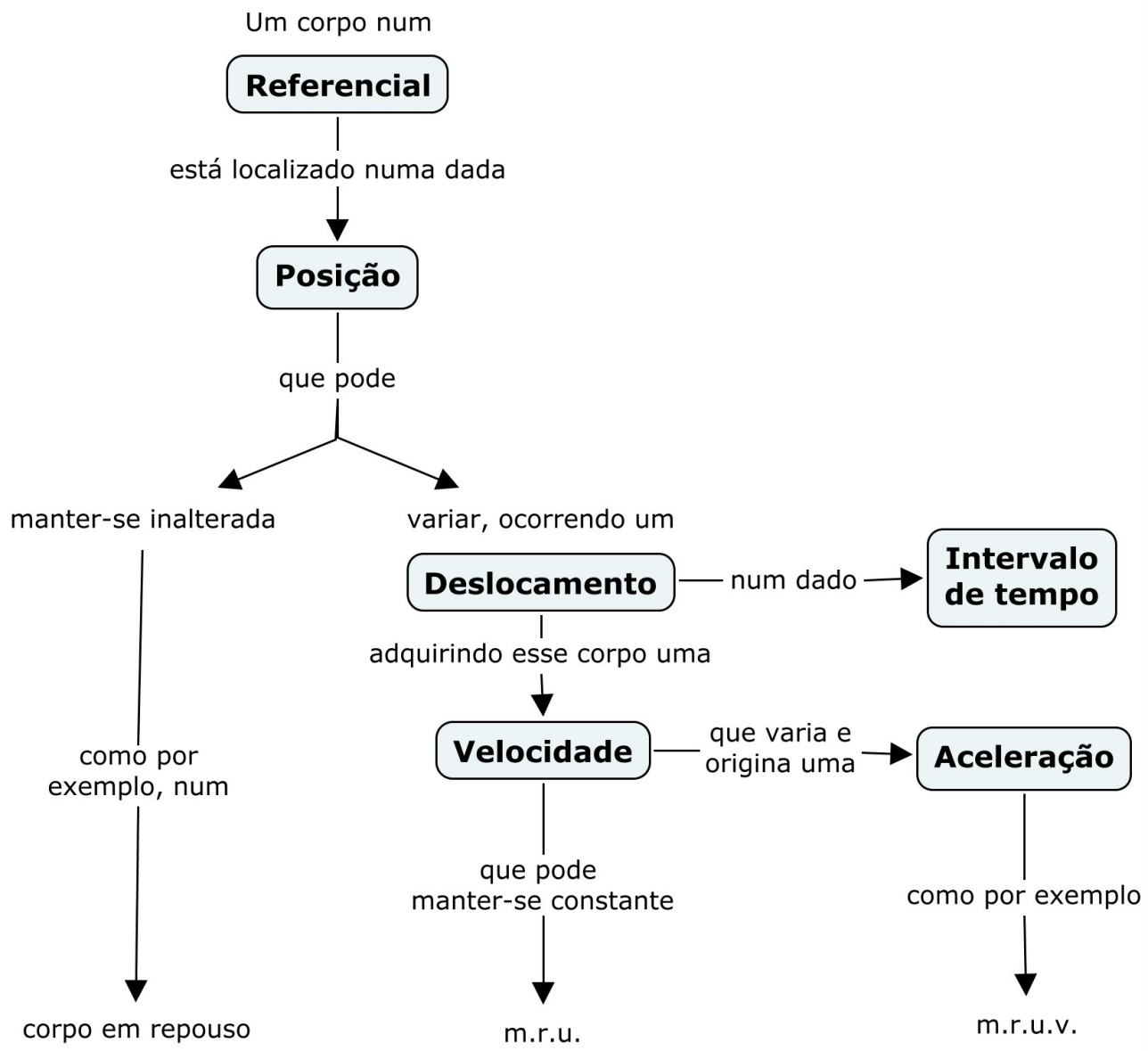

Figura 3: Mapa de Conceitos de um campo conceptual da cinemática. 
Revista do Professor de Física • Brasília, vol. 2, n. 3 • 2018

Podemos, então, resumir as vantagens da construção dos mapas conceptuais da seguinte forma:

- Possibilitam conhecer o modelo mental do aluno acerca de um dado campo conceptual, ou sobre a descrição de um fenómeno físico. Isso permite ao professor delinear estratégias e escolher recursos didáticos que auxiliem o aluno a (re)construir as suas ideias e a realizar uma aprendizagem com significado.

- Constituem uma oportunidade de elaborar sínteses de um Tópico ou Capítulo, revisitando conteúdos científicos lecionados e ajudando a enriquecer o conhecimento científico através de contextos diversificados.

- Criam uma representação construída pelos alunos a partir de uma análise discutida em grupo, onde ocorre o confronto de interpretações, a reformulação do pensamento, a conciliação de ideias e a apresentação de soluções, usando uma linguagem (a dos alunos) na qual eles próprios se reconhecem (e não a linguagem do professor, tantas vezes demasiado hermética e incompreensível).

Os MC podem ser usados em várias áreas da ciência, em particular em Física e Química, potenciando um enorme ganho de aprendizagem como resultado da evolução dos modelos mentais nos alunos (GOUVEIA; VALADARES, 2004; SANSÃO; CASTRO; PEREIRA, 2002) e sua aproximação aos modelos científicos.

\section{LOGÍSTICA NA APLICAÇÃO DO ENSINO INTERATIVO E DA IPC}

A implementação de estratégias que conduzam a um ensino interativo não obriga à remodelação dos espaços letivos, ou à aquisição de equipamento dispendioso ou tecnologicamente avançado. No entanto, é incontornável que a massificação dos recursos educativos digitais (RED) nas escolas (quadros interativos, projetores, plataformas de comunicação, internet sem fios, etc) e o acesso a meios tecnológicos (tablets, computadores e smartphones), permitem atualmente uma vasta panóplia de soluções que auxiliam o professor na transposição de um ensino tradicionalmente expositivo, para uma metodologia de ensino em que o estudante tem um papel ativo.

Assim, o professor deve fazer uma verificação cuidadosa de todos os recursos de que dispõe e que a escola lhe oferece, nomeadamente (a) as condições físicas do espaço de aula, (b) as aplicações para interação em tempo real, (c) o software de apoio a atividades didáticas e (d) as plataformas informáticas síncronas e assíncronas.

\subsection{Condições físicas da sala de aulas}

A sala de aulas tradicional, em que as mesas (ou cadeiras, no caso de um anfiteatro) estão orientadas para o professor, favorecem um ensino expositivo e centrado no orador. Este pode, a espaços, interagir com a assistência, mas torna difícil alterar profundamente o estilo da prática letiva (MAZUR, 2014).

A disposição da sala tradicional não favorece a participação do estudante no debate conceptual, nem facilita a reflexão crítica dos conteúdos com os colegas. Como resultado, é frequente ele refugiar-se na 
sua zona de conforto silenciosa. Isto priva o professor de aceder aos modelos mentais do estudante, cujo conhecimento é essencial para avaliar o grau de aprendizagem e adequar convenientemente a prática letiva.

A posição das mesas e cadeiras deve, assim, favorecer o contacto visual direto entre os estudantes, para que a discussão entre eles seja facilitada. Além disso, a disposição da sala deve permitir a circulação do professor, tornando-o sempre visível pelos estudantes. $\mathrm{O}$ desenvolvimento de competências pelos alunos não pode ser condicionado pela maneira como estão dispostos pela sala, pelo que há algumas soluções interessantes para este problema, consoante as tarefas a executar:

1. Disposição das mesas em "U" ou em quadrado (Figura 4) - com as mesas a formar um U ou um quadrado, os estudantes têm uma visão direta dos colegas. Esta disposição facilita a discussão e foca cada estudante para os colegas da frente e dos lados, com quem pode também executar pequenas tarefas em grupo. O professor pode ocupar qualquer lugar próximo dos alunos, ou optar por se colocar no centro do U ou do quadrado, onde é sempre visível;

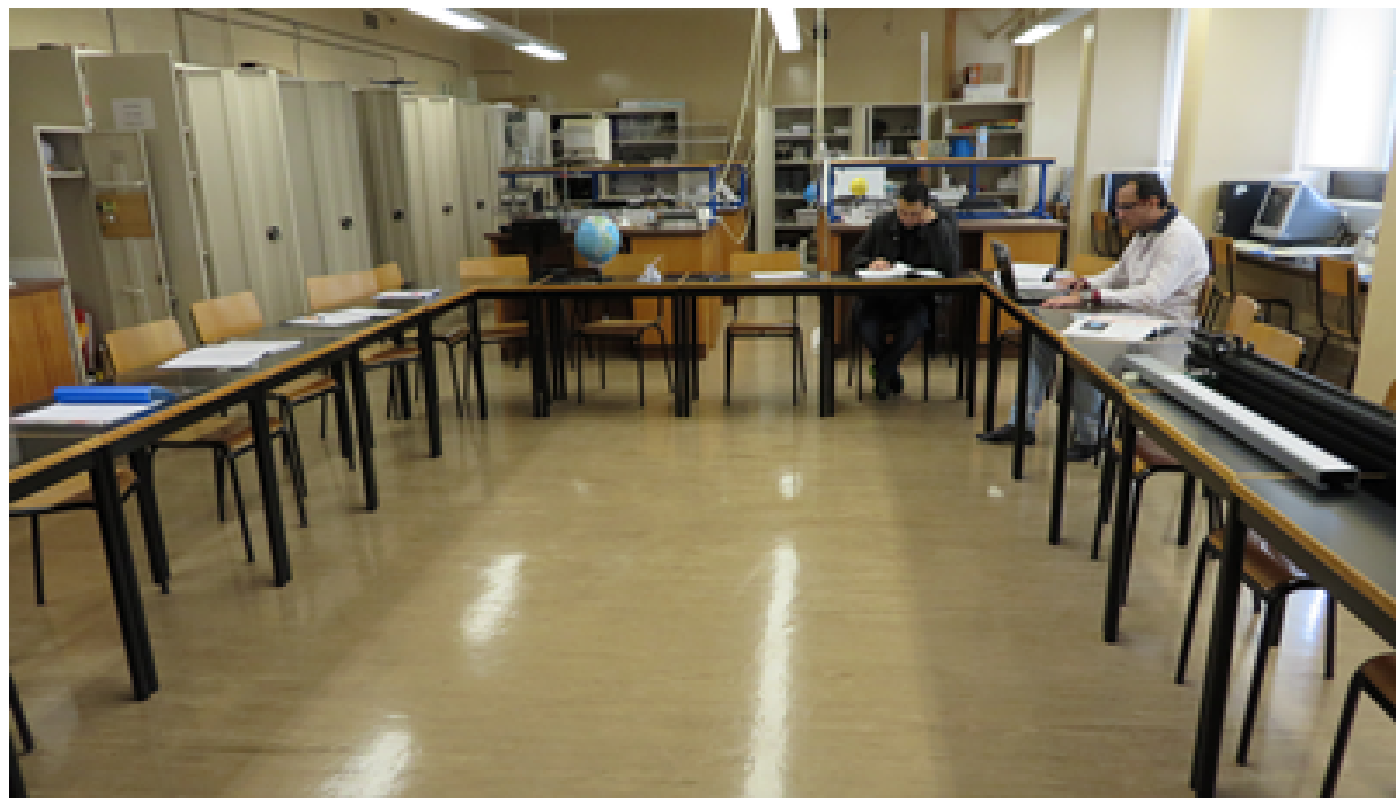

Figura 4: Exemplo da disposição das mesas em " $U$ ".

2. Disposição das mesas por "ilhas" (Figura 5) - as mesas são dispostas na forma de quadrado, círculo ou hexágono, criando "ilhas" na sala de aulas, permitindo formar grupos de trabalho. Esta distribuição facilita obviamente o trabalho de grupo e a realização de atividades de competição (por exemplo, do tipo gamificação). As "ilhas” permitem também que o professor se desloque com facilidade por toda a sala, auxiliando quando necessário o trabalho dos estudantes. Esta distribuição torna natural o acesso a recursos didáticos (livros, materiais, equipamento, computadores, ...), mas não é tão eficaz em aulas tutoriais.

A alteração entre estas duas distribuições de sala de aulas toma apenas alguns minutos (tipicamente entre dois a três, de acordo com a minha experiência), pelo que é muito fácil adequar as condições da sala às necessidades educativas. 


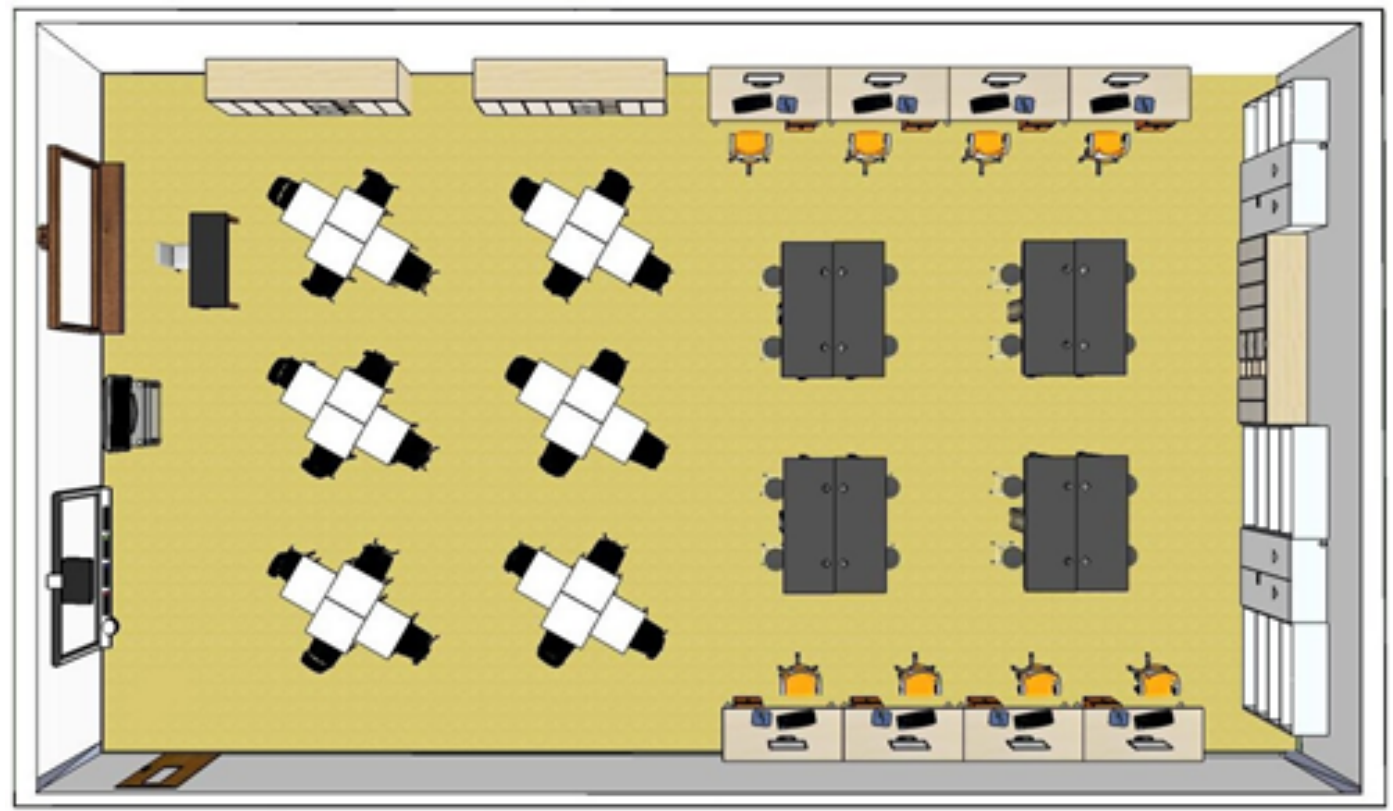

Figura 5: Exemplo da disposição das mesas em "ilhas” (CARVALHO et al., 2012).

\subsection{Aplicações de para interação em tempo real}

Nas aulas ditas tradicionais, não é habitual usarem-se aplicações em que o professor interaja com os alunos em tempo real, com exceção das situações de questão-resposta imediata. Contudo, num ensino interativo, a relação aluno-professor tem que ser privilegiada. $\mathrm{O}$ uso do quadro interativo como veículo promotor da interação entre conteúdos e recursos pedagógicos (MACHADO, 2018), os sistemas de votação eletrónica (vulgarmente designados por klickers) ou, em alternativa, as aplicações digitais análogas como o Plickers (https://www.plickers.com/) e o Socrative (https://socrative.com), ou ainda ferramentas de interação direta como o Mentimeter (https://www.mentimeter.com), têm o potencial didático de transformar uma sala de aula num contexto enriquecido de aprendizagem.

\subsection{Software de apoio a atividades didáticas}

Cada vez mais, é necessário que os alunos tenham um papel ativo fora da sala de aula. Trabalhos de preparação, consolidação e aprofundamento de aprendizagens, devem ser fornecidos aos alunos para que, gradualmente, eles possam criar autonomia no estudo e desenvolver competências conceptuais, processuais e atitudinais. Isto envolver a leitura e exploração de textos, simulações, vídeos, trabalhos de pesquisa e de projeto, os quais são frequentemente beneficiados por programas informáticos - estes deverão ser cuidadosamente escolhidos pelos professores, tendo em conta a interface visual, qualidade de utilização, potencial educativo e custo/acessibilidade pelo usuário.

Felizmente, há várias soluções disponível no mercado digital, das quais se destacam:

1. Tracker (https://physlets.org/tracker/) - programa gratuito, útil para a análise de movimentos e espectros luminosos a partir de fotos ou vídeos. Permite obter gráficos à medida que é feita 
a análise das imagens. Possui um módulo para modelação físico-matemática. Apresenta uma interface muito intuitiva. Possui filtros para criar vários tipos de contraste, efeitos de cor e imagens estroboscópicas(BROWN, 2008; BROWN; COX, 2009).

2. VirtualDub (https://sourceforge.net/projects/virtualdub/) - aplicação que separa uma porção de um vídeo em sequências de fotogramas (quadros). Concebido para obter imagens fixas de um vídeo, a serem trabalhadas individualmente ou em grupo. A qualidade das imagens não é alterada pelo programa. Distribuição gratuita.

3. ImageJ (https://imagej.net/Welcome) - aplicação científica que compila várias imagens (geradas, por exemplo, pelo VirtualDub) numa única, criando assim uma imagem estroboscópica de elevado contraste e qualidade.

4. HueAnimation (https://huehd.com/animation/) - programa comercial para criar vídeos a partir de fotografias. $\mathrm{O}$ utilizador pode escolher a taxa de quadros por minuto (qpm) e a qualidade do vídeo. Muito útil para projetos de aprofundamento da cinemática. Tem um custo muito acessível para instituições de ensino e uma versão gratuita para estudantes (embora limitada a 50 fotografias). Em alternativa, pode ser usado o MovieMaker (https://www.windows-movie-maker.org/), apenas disponível para utilizadores Windows.

\subsection{Plataformas informáticas síncronas e assíncronas}

Quando se estimula os alunos a trabalhar fora da sala de aulas, com atividades individuais ou em grupo, sejam elas de leitura, exploração ou de projeto, é lícito esperar que eles se empenhem na execução desses trabalhos. Os professores sabem que estas atividades extracurriculares auxiliam fortemente a aprendizagem dos alunos, mas esse é um benefício que eles não reconhecem de imediato. A minha experiência é que a incorporação dessas atividades, com uma percentagem nunca inferior a 5\% na avaliação global dos estudantes, introduz um fator decisivo no seu comprometimento e participação efetiva.

O problema, muitas vezes, reside em saber como avaliar de forma justa essa participação. Atualmente, existem para o efeito algumas plataformas de repositório de conteúdos, que podem ser usadas pelos professores para esse efeito. Destaco aqui duas delas, pela sua excelência educacional:

1. Perusall (https://perusall.com/) - plataforma criada por uma equipa mista das Universidades de Harvard e do Texas, é atualmente de acesso e utilização gratuita. Nela, o professor coloca textos e elabora tarefas de leitura, que os alunos deverão executar e colocar os seus comentários e/ou dúvidas. A plataforma distribui aleatoriamente os alunos em grupos de discussão, nos quais são apenas visíveis os comentários desse grupo. Contém um algoritmo de pontuação automática dos comentários dos alunos e da pontuação final da atividade, atribuída numa escala escolhida pelo professor, tendo em conta a qualidade da resposta, o número de respostas dadas e a distribuição dos comentários ao longo do texto. Possui ainda um módulo de deteção de plágio, eliminando automaticamente comentários similares previamente escritos por outro utilizador. 
2. Kahoot! (https://kahoot.com/) -plataforma de acesso gratuito, em que apenas o gestor (por exemplo, um professor) pode aceder como repositório e partilha de testes de questões. Há várias opções possíveis de jogabilidade, mas a mais usada é a elaboração de testes de questões de escolha múltipla. $\mathrm{O}$ acesso dos alunos faz-seatravés do endereço https://kahoot.it/ e é igualmente gratuito.

A realização das atividades com esta plataforma tem uma dinâmica motivacional extraordinária. A pontuação dos alunos, em modalidade individual ou em grupo, tem em conta o acerto da resposta e o tempo que levou a responder. Os alunos têm sempre acesso à sua pontuação e respetiva posição classificativa face aos colegas, promovendo um ambiente competitivo e transparente. No final, os vencedores são distribuídos num pódio, com atribuição de medalhas. Por conter vários elementos que caracterizam os jogos, a plataforma torna possível ensinar e aprender de forma participada e lúdica, num ambiente simultaneamente descontraído, divertido e sério. Esta abordagem didática está em linha com o que é hoje designado por gamificação (DETERDING; DIXON KHALED; NACKE, 2011). O Kahoot! ser também encarado, por professores e alunos, como uma ferramenta de avaliação formativa das aprendizagens dos alunos.

\section{A PEER INSTRUCTION E O ENSINO INTERATIVO}

De uma forma geral, pode-se dizer que o Ensino Interativo é toda a forma de instrução que permite ao estudante expor os seus pontos de vista, refletir criticamente e participar de forma ativa na construção do seu conhecimento.

$\mathrm{Na}$ adaptação da escola à sociedade emergente, a participação ativa dos estudantes na sua própria aprendizagem ganha, assim, um valor acrescido. Ela consegue-se atribuindo um papel interventivo ao

estudante, valorizando as suas ideias (em vez de as criticar negativamente), facilitando a sua participação (em vez de a impedir), estimulando a argumentação entre os alunos (em vez de os manter calados) e incentivando a aprendizagem em grupo (em detrimento da aprendizagem solitária). É assim que surge a Peer Instruction, ou Instrução pelos Colegas (IpC).

A IpC é uma técnica de ensino interativa vocacionada essencialmente para a sala de aulas, pela qual os estudantes aprendem uns com os outros através da discussão de conceitos. (CROUCH et al., 2007; CROUCH; MAZUR, 2001; MAZUR, 1997). A ideia fundamental da IpC é confrontar os estudantes com situações ou fenómenos intrigantes, de preferência contraintuitivos, que os leve a refletir primeiro sobre as suas ideias, depois sobre as ideias dos outros e finalmente a analisar os argumentos que as sustentam, por forma a construir finalmente uma nova e sustentável ideia. A Peer Instruction é, portanto, uma técnica de aprendizagem em grupo.

Alguns aspetos característicos da aprendizagem entre pares, são:

- - Situações de aprendizagem diferentes das oferecidas nos manuais escolares.

- Grupos de discussão de tamanho considerável (>20 pessoas).

- Ocupa uma boa parte da carga horária (cerca de 1/3 do tempo letivo).

- Necessidade dos estudantes se prepararem previamente para a aula (leitura de textos complementares, tarefas de pesquisa, exploração de simulações, análise de vídeos, ...). 
- Uso (intensivo) do raciocínio crítico durante as aulas.

- Situações de conflito ideológico e argumentação.

- Motivação (quase) permanente.

- Proximidade do professor com as reais dificuldades conceptuais dos estudantes.

A IpCé uma componente fundamental na implementação efetiva de um ensino interativo. A aprendizagem pode ser potenciada se a for complementada com estratégias de feedback, que permitam ao professor adequar as aulas e as tarefas da instrução entre pares às dificuldades dos estudantes - é o caso do Just-in-Time Teaching ou JiTT (NOVAK et al., 1999). Assim, a IpC e o JiTT produzem informações para o professor de caráter diferente: a IpC dá um feedback em tempo real, enquanto que o JiTT dá um feedback assíncrono (MAZUR; WATKINS, 2009).

\section{IMPLEMENTAÇÃO DA PEERINSTRUCTION NA SALA DE AULAS}

A dinâmica numa sala de aulas está condicionada por diversos fatores. A IpC, sendo uma componente dessa dinâmica, não é exceção. Só existe uma verdadeira interatividade entre os estudantes quando a temática em debate é motivadora, os conteúdos são minimamente conhecidos pelos estudantes (não se pode debater o que não se sabe!) e existe uma pluralidade de opiniões (divergentes ou convergentes, mas diferentes) sobre o assunto.

Assim, é fundamental uma escolha cuidadosa das questões a apresentar aos estudantes, preferencial-

mente de caráter contraintuitivo. A tomada de decisão sobre como proceder face às respostas dos alunos é da responsabilidade do professor, tendo em conta a qualidadedas intervenções e dos conteúdos em debate. Assim, ele terá de decidir se há necessidade de revisitar os conteúdos, se avança com o debate conceptual ou se passa de imediato para a explicação do problema/questão ou fenómeno. Podemos sintetizar essas escolhas na Figura 6 (LASRY; MAZUR; WATKINS, 2008).

\section{RECURSOS EDUCATIVOS E A PEER INSTRUCTION}

Há diversas abordagens didáticas e Recursos Educativos que ajudam a implementar um ensino e aprendizagem interativo, dentro e fora da sala de aulas.Alguns exemplosdesses recursos são as Questões Conceptuais (QC) estáticas e dinâmicas, as Atividades Experimentais Virtuais (AEV), os Questionários (Quizzes), os Roteiros de Exploração de Vídeo Educativo (REVE) e de Software Educativo (RESE) (QUINTAS, 2012), as Atividades Experimentais Baseadas em Vídeo (AEBV), a Aprendizagem Baseada em Computadores (ABC) - Microcomputer Based Learning (SOKOLOFF; LAWS; THORNTON, 1999-2004), entre outras (CARVALHO, 2015). A característica comum a todos estes recursos é que favorecem o envolvimento ativo dos alunos em atividades práticas (hands-on) e exigem uma atitude reflexiva e crítica (heads-on)do trabalho realizado. 


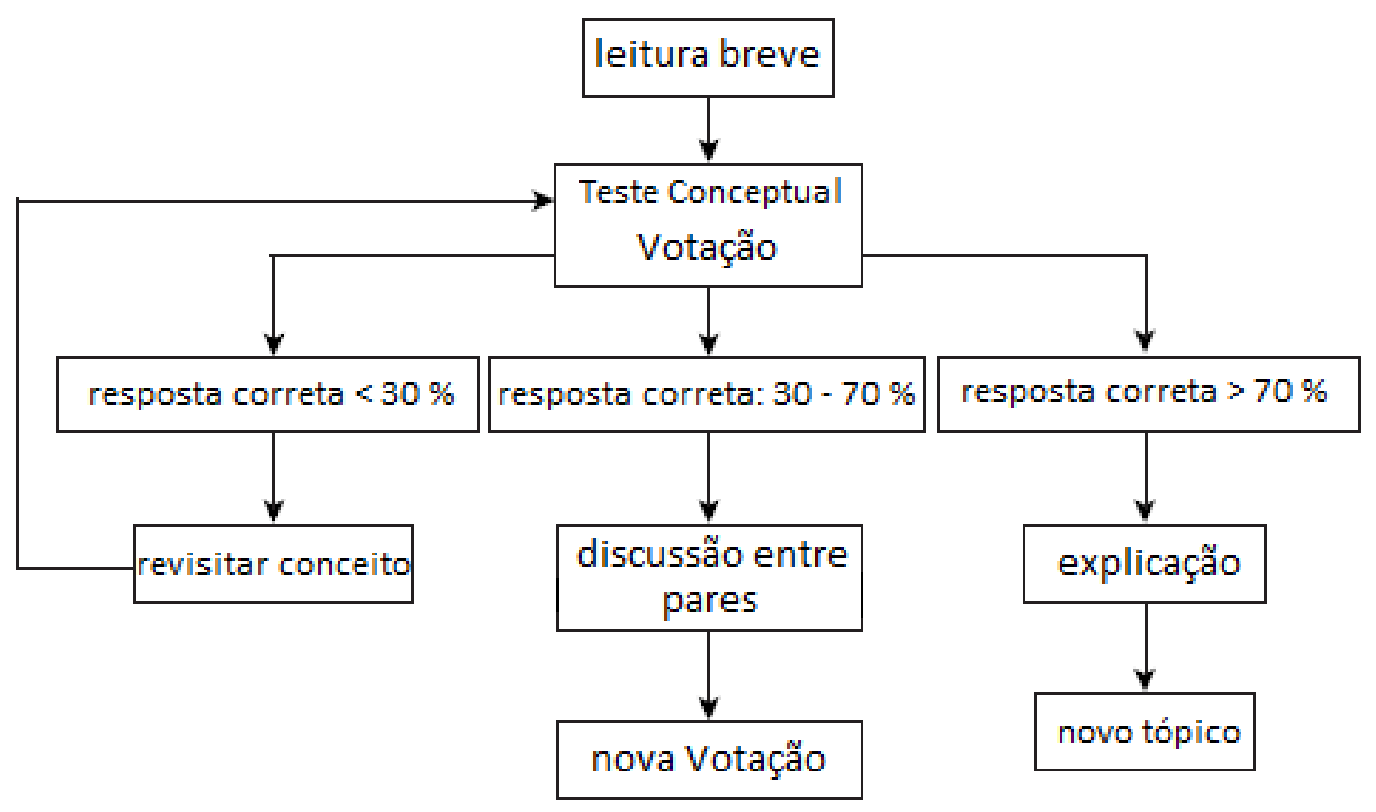

Figura 6: Esquema de implementação da instrução entre pares: apenas para respostas corretas entre 30 e $70 \%$ é que a discussão entre pares é relevante. Os valores percentuais indicados são estimativas. Adaptado de LASRY; MAZUR; WATKINS (2008).

Com a aplicação da IpC na sala de aulas procura-se que os estudantes debatam ideias, desenvolvam capacidades de argumentação das suas posições e façam uso de uma linguagem científica apropriada. A interpretação de um fenómeno ou situação física deve ser conseguida pelo próprio estudante, expondo o seu modelo mental, confrontando-o com o dos colegas e aferindo o que é (e o que não é) uma ideia científica coerente. Neste processo, o papel do professor é maioritariamente o de orientar a discussão, abstendo-se o mais possível de mostrar preferência por esta ou aquela ideia em debate e questionando frequentemente as opiniões dos estudantes, mesmo aquelas que ele sabe estarem corretas (esta é uma forma de testar a coerência e solidez do modelo mental desses estudantes).

Independentemente dos materiais usados na implementação de um ensino interativo (questões conceptuais, animações, vídeos, questionários, etc.) com recurso à IpC,os resultados conhecidos da literatura conduzem sempre a aprendizagens com maioresganhos de aprendizagem (HAKE, 1998) que o ensino tradicional.

\section{CONSIDERAÇÕES FINAIS}

O uso concomitante das várias soluções educativas apresentadas e de forma diversificada, é provavelmente a chave de sucesso do ensino interativo. É necessário que se tome consciência de que as ferramentas e os recursos educativos não garantem a aprendizagem, mas auxiliam (e muito) o professor a implementar metodologias ativas, que estimulam os alunos a intervir e a dar feedback da sua aprendizagem.

Mais do que mais ummétodo de ensino, a IpC é uma abordagem que potencia a aprendizagem dos 
alunos, permitindo-lhes expressar as suas ideias usando a sua própria linguagem, fator essencial para uma aprendizagem efetiva (ARONS, 1997). Na base da IpC e de todo o ensino interativo, está o confronto dos modelos mentais dos estudantes que conduzem à reconstrução do pensamento científico, promovendo assim a sua aproximação aos modelos físicos que fundamentam o conhecimento científico (HESTENES, 1987).

A implementação, pelo professor, da IpC e de abordagens como o JiTT potenciadoras do ensino interativo e de uma aprendizagem significativa, não é imediata nem se adquire apenas vendo alguém a fazê-lo ou lendo trabalhos sobre o assunto. Aprende-se fazendo, alterando metodicamente a forma de ensinar e experimentando as (novas) soluções educativas, sempre acompanhadas por uma avaliação dos estudantes que valorize o seu empenho, o progresso na aprendizagem, o trabalho experimental, o saber trabalhar em grupo e, de um modo geral, as competências adquiridas. Só desta forma se poderá mudar uma Escola, em que o Saber e o Ser são componentes essenciais para a civilização futura.

\section{Referências}

ABRAHAMSON, A. L. An overview of teaching and learning research with classroom communication systems (ccss). In: Atas da International Conference of the Teaching of Mathematics. Samos, Grécia: John Wiley \& Sons, Inc., 1998.

ARONS, A. Teaching Introductory Physics. New York: John Wiley \& Sons, Inc, 1997.

AUSUBEL, D. P. Educational Psychology: a cognitive view. New York: Holt Rinehart and Winston, 1968.

BAO, L.; REDISH, E. American Journal of Physics, v. 69, n. 7, p. Supplement, S45-S53, 2001.

BROWN, D. Video modeling: Combining dynamic model simulations with traditional video analysis. In: Atas da American Association of Physics Teachers (AAPT) Summer Meeting. Edmonton: [s.n.], 2008.

BROWN, D.; COX, A. The Physics Teacher, v. 47, p. 145-150, 2009.

CARVALHO, P. Peerinstruction como estratégia metodológica para o ensino da física. In: Atas do XXI Simpósio Nacional em Ensino da Física. Uberlândia, Brasil: [s.n.], 2015. p. 599-618.

CARVALHO, P. S. et al. Ensino Experimental das Ciências: um guia para professores do Ensino Secundário - Física e Química. Porto: Editorial UP, 2012.

CROUCH, C. H.; MAZUR, E. American Journal of Physics, v. 69, n. 9, p. 970—-977, 2001.

CROUCH, C. H. et al. Peer instruction: Engaging students one-on-one, all at once. In: REDISH, E.; COONEY, P. (Ed.). Research-Based Reform of University Physics. [S.1.]: Reviews in Physics Education Research, 2007. v. 1, n. 1, p. 40-95. Disponível em:<http://www.compadre.org/per/per_reviews/volume1.cfm>.Acesso em: 01/02/2018). 
DETERDING, S.; DIXON KHALED, D.; NACKE, L. From game design elements to gamefulness: Defining 'gamification'. In: Atas da 15th International Academic MindTrek Conference. Tampere, Finlândia: [s.n.], 2011.p. 9-15.

ETKINA, E.; WARREN, A.; GENTILE, M. The Physics Teacher, v. 44, n. 1, p. 34-39, 2006.

FILHO, N. S. Games e gamificação no ensino de física. In: Atas da VI Escola de Física Roberto A. Salmeron/I International School on Physics Teaching. Brasília: [s.n.], 2017.

GOUVEIA, V.; VALADARES, J. Concept maps and the didactic role of assessment. In: CAñAS, A. J.; NOVAK, J. D.; (ORG.), F. M. G. (Ed.). Atas da First International Conference on Concept Mapping. Pamplona, Espanha: [s.n.], 2004.

HAKE, R. American Journal of Physics, v. 66, n. 1, p. 64-74, 1998.

HESTENES, D. American Journal of Physics, v. 55, p. 440—-454, 1987.

JOHNSON-LAIRD. P.N.Mental Models: Towards a Cognitive Science of Language, Inference, and Consciousness. Cambridge, Massachussets: Harvard University Press, 1983.

JOWETT, B. The Dialogues of Plato: Translated into English, with analyses and Introductions - Volume I. New York: Charles Scribner's Sons, 1911.

LASRY, N.; MAZUR, E.; WATKINS. J. American Journal of Physics, v. 76, p. 1066-1069, 2008.

MACHADO, C. Simulador no Quadro Interativo: Impactos no Ensino e Aprendizagem da Física. Tese (doutoramento em Ensino das Ciências - ramo de Ensino da Física) — Universidade de Coimbra, Coimbra, 2018.

MAZUR, E. Peer instruction: a user's manual. Upper Saddle River, New Jersey: Prentice Hall, 1997.

MAZUR, E. The scientific approach to teaching: Research as a basis for course design. In: Atas da International Conference Teaching/Learning,Physics: Integrating Research into Practice (MPTL-GIREP). Palermo, Itália: [s.n.], 2014. p. 52.

MAZUR, E.; WATKINS, J. Just-in-time teaching and peer instruction. In: SIMKINS, S.; MAIER, M. (Ed.). Just in Time Teaching Across the Disciplines. Sterling: Stylus Publishing, 2009.

MOREIRA, M. Investigações em Ensino de Ciências, v. 7, n. 1, p. 7-29, 2002.

NOVAK, G. et al. Just-in-Time Teaching: Blending Active Learning with Web Technology. New Jersey: Upper Saddle River, Prentice Hall, 1999.

NOVAK, J. D.; GOWIN, D. B. Aprender a Aprender. Lisboa: Plátano Edições Técnicas, 1996.

PIRES, A. A evolução das idéias da Física. S. Paulo: Editora Livraria da Física, 2008. 
QUINTAS, M. Atividades sobre o Som, no âmbito de um clube de ciências envolvendo o Ano Internacional do morcego. Dissertação (mestrado em Física e Química em Contexto Escolar), Porto, 2012.

SANSÃO, O.; CASTRO, M.; PEREIRA, M. Mapa de conceitos e aprendizagem dos alunos. Lisboa: Instituto de Inovação Educacional, 2002.

SERZEDELLO, M. Física!? isso para mim é grego! Coleção Produção Acadêmica, São José do Rio Preto, 2012.

SOKOLOFF, D.; LAWS, P.; THORNTON, R. Realtime physics, active learning laboratories, modules 1-4. John Wiley \& Sons, Inc., New Jersey, 1999-2004.

VERGNAUD, G. Recherches en Didactique des Mathématiques, v. 10, n. 23, p. 133-170, 1990. 